\title{
Imipramine Effects on Sleep in Depressed Adolescents: A Preliminary Report
}

\author{
Benjamin N. Shain, Michael Naylor, James E. Shipley, and
} Norman Alessi

\section{Introduction}

Antidepressant medications, including tricyclic antidepressants, monoamine oxidase inhibitors, lithiun, and fluoxetine, generally have been found to suppress rapid eye movement (REM) sleep (von Bardeleben et al. 1989, reviewed by Saletu 1986), although several unusual antidepressants have been found to increase REM sleep (Wiegand et al. 1986; Di Perri et al. 1987; Soldatos et al. 1988; Monti 1989). Additional evidence that there may be an association between the antidepressant $e f-$ fects of the medications and their $\bar{R} E M i$ sleep effects include the following: (1) The extent to which amitriptyline (Kupfer et al. 1976; Gillin et al. 1978; Kupfer et al. 1981) and clomipramine (Höchii êt ât: 1986) suppress REM sleep was found to predict eventual antidepressant response in depressed adults. Kupfer et al. (1979) extended these findings into depressed children treated with imipramine. (2) Selective REM sleep deprivation improved depressive symptoms (Vogel et al. 1975). Eight of 9 subjects unresponsive to selective REM sleep deprivation were also unresnonsive to imipramine.

Characteristic sleep abnormalities found in depressed adults have not been consistently

\footnotetext{
From the University of Mishigan, Department of Psychiatry, Ann Arbor, Mii.

Address reprini requests to: Benjamin Shain, M.D., Ph.D., University of Michigan; Department of Psychiatry, Child and Ado-

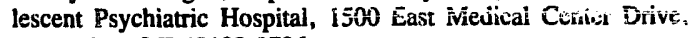
Ann Arbor, MI 48109-0706.

Received August 2?. 1989; revised January 22, 1990.
}

demonstrated in depressed adolescents. In a study consisting largely of outpatients, Goetz et al. (1987) anc Appelboom-Fondu et al. (1988; noted only some sleep continuity disturbances and not the other characteristic abnormalicies: rediced delta sleep, increased REM density during the early part of the night, and shortened REM latency (Kupfer et al. 1985). Enslie et al. (1987) found all four abnormalities in a sample of inpatients, as did Lahmeyer et al. (1983) in a sample of inpatients and outpatients.

As yet, no studies have found thät tuicyclic antidepressant therapy is more effective than placebo in the treatment of adolescent depression (Kramer and Feiguine 1981; Ryan et al. 1986). This raises the question of whether or not tricyclic antidepressant medications cause changes in REM sloep parameters in adolescents similar to those caused in adults. REM sleep changes reported in depressed achults on tricyclic antidepressants include increased REM latency and decreased REM time, REM activity, and number of REM neriods i jarrett et al. 1988; Höchli et at. 1986: Kupter et al. 1981). We are not avsare of studies on the effects of these medications on sleep in depressed adolescents. The present study examinec' the acute effects of imipramine on electroencephalogram (EEG)-monitored sleep in adolescents with major depressive disorder (MDD).

\section{Methods}

The subjects were 10 inpatients admitted to the Universiry of Michigan Medical Center Ado- 
lescent Psychiatry Urit, a 14-bed clinical research unit. Informed consent was obtained. The sample included 6 girls and 4 boys, with a mean age of 15.1 years and an age range of 13-17 years. The diagnosis of primary uripolar MDD was made by an attending child psychiatrist according to Research Diagnostic Criteria (Spitzer et al. 1978), using information from a multidisciplinary evaluation and a semistructured interview with the Schedule for Affective Disorders and Schizophreria (Endicott and Spitzer 1978). Seven of the patients had the endogenous subtype and 4 had distinct comorbid diagnoses, according to DSM-111-R: panic disorder with agoraphobia ( $3 \mathrm{p} c$ rients) and a combination of panic disorder with agoraphobia, obsessive compulsive disorder, and conduct disorrer (1 patient). All adolescents were depressed throughout an initial 2-6 wcek medication-free assessment period. On the first week of slecp studies, scores on the 17-item Hamilton Leprtession Rating Scale (Hamilton 1960) ranged from 11 to 27 with a mean of 19.0 .

The adolescents were studied polysomnographically for two rairs of consecutive nights 1 week apart. The studies were performed using an EES sleep telephone telemetry system (TeleDiagnostic Systems, San Francisco) which enabled data to be telemetericu from inpaicients in their own jeds to the sleep laboratory control room. The studies were otherwise performed and analyzci as described previously (Grunhaus et al. 1988). The patients were psychot'cpic medication-free on nights 1 and 2. Nights 3 and 4 were the first two nights of treatment with 50 mg of imipramine at 9:00 PM. Nights 1 and 3 were considered adaptation nichts. Mean values of selected sleep variables were compared between night 2 íaseline) and night 4 (imipra. mine) with a two-tailed, paired $i$-test.

\section{Resuilts}

Significant REM suppression was found cn iinipramine compared to baseline (Table 1). We found an increase in REM latency $(p<0.041)$ and decreases in REM time $(p<0.0001)$, REM percent $(p<0.0001)$, REM aciivity $(w<0.001)$, and sumber of REM periods ( $p<0.0001)$. REM density did not change significantly. Percent of stage 1 sleep increased $(p<0.05)$, with no significant differences in percent : stage 2 or delta sleep. No sleep continuity variables were significantly different, although increased number of arousals showed a trend toward significance.

\section{Discussion}

Imipramine markedly suppressed REM sleep in depressed adolescents, and had only minor effects on sleep continuity (a trend toward increased number of arousals) and sleep architecture (increased percent of stuge 1 sleep). These findings were similar to those in depressed adults. Ianctt et al. (1988) reported increased REM latency; decreased REM time, REM activity, REM density. and number of REM periods; and no significant sleep continuity changes on the first night of treatment with imipramine. The sleep archirecture changes were different in adults: increased fercent of stag: 2 sleep and no change in percent of stage 1 sleep (Jarrett et al. 1988). Kupfer et al. (1979) found some similarities and differences in REM sleep in depressed children who had been taking imipramine for 3 weeks. Similarities included increased REM latency, and decreased percent of REM and number of REM periods. Differences included not significantly changed REM activity and increased REM density. There were also more inipramine-induced disturbances in sieep continuity and nonREM sleep architecture. The differences with the current findings may have been due to the fact that sleep studies were done after 3 weeks of imipramine, rather than on night 2 of imipramine.

The current findings suggest that effects of inipramine on REM sleep in depressed adolescents are similar to effects on REM sleep in depressed adults. Further work is indicated, including investigations of the association between antidepressan:-induced changes in EEGmonitored sleep and clinical response to the medication. 
Table 1. Selected Sleep Variables

\begin{tabular}{|c|c|c|c|c|c|c|}
\hline \multirow[b]{2}{*}{ Sleep variable } & \multicolumn{2}{|c|}{ Baseline } & \multicolumn{2}{|c|}{ On imipramine } & \multirow[b]{2}{*}{$t^{3}$} & \multirow[b]{2}{*}{$p<$} \\
\hline & Mean & (SD) & Mean & (SD) & & \\
\hline \multicolumn{7}{|l|}{ Sleep continuity variables } \\
\hline Total recording period (min) & 427.5 & (26.7) & 439.3 & (20.2) & -1.06 & NS \\
\hline Sleep latency $(\mathrm{min})$ & 49.9 & (30.8) & 49.3 & (35.2) & 0.04 & NS \\
\hline Number of arousals & 0.4 & (0.7) & 2.5 & (2.5) & -2.24 & 0.10 \\
\hline Time spent asleep (min) & 372.2 & (50.2) & 373.8 & (40.3) & -0.13 & NS \\
\hline Efficiency $($ TSATTR $\times 100)$ & 86.9 & (8.8) & 85.1 & (7.9) & 0.58 & NS \\
\hline \multicolumn{7}{|l|}{ Sleep archiiterture } \\
\hline Stage $1 \%$ & 6.7 & (4.2) & 14.8 & (9.7) & -2.53 & 0.05 \\
\hline Stage $2 \%$ & 50.6 & (4.7) & 54.0 & (i1.1) & -1.02 & NS \\
\hline Delta \% & 26.7 & (7.2) & 27.9 & (9.0) & -0.81 & NS \\
\hline REM \% & 16.1 & (3.2) & 3.3 & (3.5) & 9.56 & 0.0001 \\
\hline \multicolumn{7}{|l|}{ REM sleep variables } \\
\hline REM latency (min) & 107.7 & (42.9) & 312.6 & (55.1) & $-6.95^{b}$ & $0.00 !$ \\
\hline REM time (min) & 59.8 & (14.2) & 12.2 & (13.2) & 8.90 & 0.0001 \\
\hline REM activity (U) & 61.4 & (24.3) & 8.7 & (11.0) & 3.64 & 0.001 \\
\hline REM density & 10 & $(0.4)$ & 0.8 & (0.2) & $1.2^{b}$ & NS \\
\hline No. of REM periods & 3.5 & $(0.7)$ & 0.7 & (0.5) & 9.64 & 0.0001 \\
\hline
\end{tabular}

Two-tailed, paired $t$-test; $\mathrm{df}=9$ unless otherwise indicated.

${ }^{b}$ No REM sleep during 3 of the imipramine nights; $d f=6$.

\section{References}

Appleboom-Fondu J, Kerkhofs M, Mendlewicz J (1988): Depression in adolescents and young adults-Polysomnographic and neurcesidocrine aspects. $J$ Affective Disord 14:35-40.

Di Perri R, Mailland R, Bramanti P (1987): The effects of amineptine on the mood and nocturnal sleep of depressed paiients. Prog Neuropsychopharmacal Biol Psychiatr; 11:65-70.

Ernslie GJ, Roffwarg HP, Rush AJ, Weinberg WA, Parkin-Feigenbaum $\mathbf{i}$ (1987): Sieep EEG findings in depressed children and aciolescents. Am J Psychiatry 144:668-670.

Endicott I, Spitzer RL (1978): A diagnostic interview. Asch Gen Psychiatry 35:837-844.

Gillin JC, Wyatt RJ, Fram D, Snyder F (19;8): The relationship between changes in REM sleep and clinical iniprovement in depressed patients treit:ed with amitriptyline. Psychopharmacology 49:267. 272.

Goetz riR, Puig-Antich J, Ryan N, et al (1987): Electivencepholograyhic jleep of adolescents with major depression and normal controis. Arch Geri Psychiatry 44:51-68.

Grinhaus L, Tiongco D, Pande A, et al (1988): Monitoring of antidepressant response to ECT with polysomnographic recordings and the dexameth- asone suppression test. Psychiatry Res 24:177185.

Haniiton îj (1960): A rating scale for depression. $J$ Neurol Neurosurg Psychiatry 23:56-62.

Höchli D, Riemann D, Zullcy J, Berger M (1986): Initial REM sleep suppression by clomi, ramine: A prognostic tool for treatment response in patients with a major depressive disorder. Biol Psychiatry 21:1217-1220.

Jarrett DE, Miewald JM, Kupfer DJ (1988): Acute changes in sleep-related homuine secretion of depressed patients following oral imipramine. Biol Psychiatry 2A.541-554.

Kramer AD, Feiguine RJ (1981): Clinical effects of amitriptyline in adolescent de ression. J Am Acad Child Psyshiaty Zú.î́,641.

Kupier DJ, Coble P., Kane J, Petii T, Conners CK (1979): Imipramine aña EEG sleep in children with depressive symptorns. Psychopharmacology 60:117-123.

Kupfer DJ, Foster G, Reich L, Thompson KS, Weiss B (1976): EEG sleep changes as predictors in depression. Am J Psychintry 133:522-626.

Kupfer DJ, Spiker DG, Coble PA, Neii JF, Ulrich R, Shaw Dif (1981): Sleep and treatment prediction in endogenous depression. Am J Psychiatry 138:429-434.

Kupfer DJ, UI sh RF, Coble PA, et al (1985): Elec- 
troencephalographic sieep of younger depressives. Arch Gen Psychiatry 42:806-810.

Lahmeyer HW, Poznanski EO, Bellur SN (1983): EEG sleep in depressed adolescents. Am J Fsychiatry 140:1150-1153.

Monti IM (1989): Effect of a reversible monoamine oxidase-A inhibitor (moclobemide) on sleep of depressed patients. Br J Psychiatry 155(Suppl 0):01-65.

Ryan ND, Puig-Antich J, Cooper T, et al (1986): Imipramine in adolescent major depression: Plasma level anu clinical iespipuise. Acia Psychiatr Scand 73:275-288.

Saletu B (1986): Therapy for sleep disorders in depressives. Psychopathology 19(Suppl 2):239-262.

Soldatos CR, Stefanis CN, Bergiannaki JD, Christodoulou C, Botsis A, Sakkas PiN (1988): An experimental antidepressant increasis REM sleep.
Prog Neuropsychopharmacol Biol Psychiatry 12:899-907.

Spitzer RL, Endicott J, Robins E (1978): Research Diagnostic Criteria. Arch Gen Psychiatry 35:773782.

Vogel GW, Thurmond A, Gibbons P, Slcan K, Boyd M, Walker M (1975): $R E M$ sleep reduction effects on depression syndromes. Arch Gen Psychiatry 32:765-777.

von Bardeleben U, Holsboer F, Gerken A. Benkert $\mathcal{O}$ (1989): Mood elevating effect of fluoxetine in a diagnostically homogeneous inpatient population with major depressive disorder. Int Clin Psychopharmacol 4(Suppl 1):31-35.

Wiegand $\mathbf{M}$, Berger M, Zuliey J, von Zerssen D (1986): The effect of trimipramine on sleep in patients with major depressive disorder. Pharmacopsychiatry 19:198-199. 